\title{
An Analytical Framework to Incorporate ICT as an Independent Variable
}

\author{
Matías Dodel
}

This chapter presents an analytical framework to guide the assessment of information and communications technologies' (ICTs) impact on individual-level development (or wellbeing). Based on the content analysis methodology, we argue that the amount of polysemy and lack of common basic guidelines in ICT's research fields constitute one of the main barriers both to the incorporation of ICT into a broader research problems spectrum (outside the ICT researchers' communities) and, consequently, to widen ICT's impact research. After a synthesis of the historical development of the digital divide concept (a framework for the analysis for digital inequalities), we discuss and select some plausible analytical models to assess ICT's impact on wellbeing. Based on Selwyn's approach, we advocate the idea that every researcher testing an ICT-related hypothesis should analyse at least three stages of hierarchical digital achievements (access, usage and appropriation) plus one last divide stage: ICT's outcomes (measured by the effect of previous stages on the dependent wellbeing variable). Finally, we propose some guidelines for the applications of this framework and present an actual case of use, showing how this framework guided the research design of this author's SIRCA II's project, which tested the effect of digital skills on education-to-work transition.

\section{Introduction}

From the richest to the poorest countries, ICT has already shaped the way we live in contemporary societies: in the Information Age, knowledge is a critical resource and information is a primary commodity (Flor 2001: p. 3). And, thus, the way we

\footnotetext{
M. Dodel $(\bowtie)$

Department of Social \& Political Sciences, Catholic University of Uruguay, Montevideo, Uruguay e-mail: matias.dodel@ucu.edu.uy
} 
work and research, talk and communicate with each other (Castells 2005: p. 88) and also the way we participate in our societies have changed dramatically.

Taking these ideas as foundations, we hypothesize that from a sociological point of view, the centrality of ICT in our lives has achieved a similar level of relevance as, e.g. progress education or gender, and thus it should be understood as a key independent variable for studying an array of diverse social phenomena.

This chapter attempts to address the problem that although most social scientists share the general idea of ICT relevance to micro- or individual-level development achievement (from now on referred to as wellbeing ${ }^{1}$ ), there are relatively few studies that consider the effects of ICT outside the fields of information society or ICT for Development (ICTD). There are probably multiple and complex causes for this, but based on the experiences acquired from collaborating with scientists and colleagues who were not specialized on the topic, we propose that at least one cause arises from some characteristics of ICT studies' field itself.

As ICT inequalities (a concept we have embedded in the digital divide) are a multidimensional phenomenon that involves several theoretical levels, conceptualization and operationalization are particularly difficult to integrate into nonspecific ICT research. Furthermore, we believe that the main cause of this problem comprised of a combination of (1) polysemy regarding key terminology in the information society field and (2) the lack of consensus on basic analytical and methodological measurement guidelines, consequently raising the barriers to entry in the field.

From this perspective, this chapter aims to present an analytical framework that links ICT inequalities to wellbeing, a digital divide analytical model that will be useful to assess ICT's effect as an independent variable or dimension on any nonICT wellbeing-dependent variable. We argue that this model or tool is crucial because it aids to reduce some of the barriers to entry mentioned above, for a particular audience outside our field.

With this goal in sight, the document is structured into three sections:

1. An overview of the conceptual development and evolution of the digital divide (understood as different levels of inequality in ICT). After stating the consequences of the lack of basic analytical consensuses, we emphasize the importance of addressing multiple hierarchical and coexisting levels of divide (access, usage, appropriation), as well as the assessment of a "final" level or dimension focusing on the impacts of ICT on the wellbeing.

2. The proposal of two plausible analytical models (one using a capabilities approach and another based on Selwyn's model of digital divide) for addressing ICT inequalities, reasonable but practical enough to be adopted by researchers outside specific ICT studies. Selwyn's model (2004, 2010) not only successfully

\footnotetext{
${ }^{1}$ For example, quality of life, social equity, education, health and income levels of individuals and families.
} 
complies with the key issues reviewed in the first section but is widely operational. Therefore, we advise the adoption of this model.

3. The description of a case of use of the analytical framework, presenting some basic guidelines for its application while showing how it guided the authors' research design in testing the effect of digital skills on education-to-work transition.

\section{The Evolution of ICT Inequalities' Conceptualization and Their Link with Development}

\subsection{The Problem of "ICT4D Polysemy"}

It is highly likely that whoever tries to enter the study of information society and ICT4D faces a first great barrier typical of fields with relative novelty: the lack of major agreements about main conceptual categories and operative terminologies. The relative time proximity of the phenomenon, as well as the complexity and acceleration of ICT developments, makes it extremely difficult to reach a point of maturity of the field which allows generating minimum agreements and consensus.

This characteristic of the field is considered to be of relative seriousness, to such an extent that specialized bibliography of more specific subtopics (e.g. digital literacy) begins its works stating explicitly the difficulty of this polysemy and the lack of conceptual maturity causes. As Lanksher and Knobel propose: "the most immediately obvious facts about accounts of digital literacy are that there are many of them and that there are significantly different kinds of concepts on offer" (Lankshear and Knobel 2008: p. 2).

This makes it difficult to select a suitable set of relevant background and findings, as well as to establish a proper analytical conceptual framework that, in terms of Bunge, possesses both a pertinent range to achieve a theoretical level that allows its operation and connection with other theories (Bunge 1999: p. 176) and depth to give account of its components and mechanisms ("translucent box" or at least "grey box" models in contrast to "black box" models; Bunge 1999: p. 178-180).

Furthermore, Peña-López (2009: p. 42) states that this conceptual ambiguity has severe sociopolitical consequences: without clear conceptual and analytical frameworks, it is difficult to evaluate the impact and reduction of the divide. This opens the path for political discretional ICT strategies and policies to the detriment of technical and social criteria.

\subsection{Digital Divide}

Despite the current extension of the term, the first governmental enunciation of "digital divide" is recent and can be attributed to the 1990s Clinton Administration 
in the United States (Peña-López 2009: p. 42). The fact is, as Rivoir et al. (2010: p. 1) state, the concept is complex and has suffered diverse mutations in the course of time.

The recent popularization and increasing relevance of the term has produced a higher inclination of national states to influence ICT development, but it did not generate major agreements in the conceptualization of the phenomenon: "Yet, while substantial policies are being put into place to combat the digital divide, much of the surrounding debate remains conceptually oversimplified and theoretically underdeveloped" (Selwyn 2004: p. 343).

Moreover, beyond the vague common idea of a division generated or caused by ICT, the diversity of uses and conceptualization of the divide is huge. ${ }^{2}$ As a way of presenting a brief summary, we have reviewed empirical studies dedicated to studying divides related to ICT (e.g. ITU 2010; Sunkel et al. 2010), benchmarking exercises (Cobo 2009; Peña-López 2009) and conceptual frameworks (i.e. Kaztman 2010; Selwyn 2004, 2010).

Regarding discipline approaches, the wide majority of the reviewed literature has been mainly dedicated to social or socioeconomic dimensions that cause or are consequences of the divide or both. Although due to the characteristics of the issue themselves, the field is intrinsically cross-disciplinary. ${ }^{3}$

\subsection{Digital Divide's Conceptual Development}

We have identified at least four stages considered as key factors in the historical and conceptual development of the divide: (1) discarding excessive technological optimism, (2) criticism to the dichotomous conception of access, (3) studying simultaneous but different levels or stages at which divides exist and (4) the divide's conceptualization model that must include ICT's impact on wellbeing as a final stage. These stages are briefly characterized below.

The overly optimistic beginnings of the divide's studies proposed that the mere introduction of ICT on country or household levels or both would practically revert poverty and inequality historical conditions. These technological deterministic origins, which stood on the initial potentials of technological breakthroughs, have almost no current serious adherents. Arguments for leaving behind this initial optimism of ICT4D are supported by recent empirical evidence at both international

\footnotetext{
${ }^{2}$ It is worth stating explicitly that this position is not new or innovative on this document. Already in 2003, Fink and Kenny faced the same dilemma: "The term of digital divide came to prominence more for its alliterative potential than for its inherent terminological exactitude. In another world we might have had the 'silicon split,' the 'gigabyte gap' or the 'pentium partition.' As such, it would be wrong to ponder for too long on what, exactly, should be meant by the term" (Fink and Kenny 2003: p. 2).

${ }^{3}$ For example, texts from education (OECD 2010; Prado et al. 2009), economics/business (e.g. White et al. 2011) and psychology (Thatcher and Ndabeni 2011; Reig 2012) have been revised.
} 
(e.g. Peña-López 2009; ITU 2010) and national country levels (e.g. in Uruguay, Rivoir et al. 2010; Moreira 2010; in Brazil, Cetic.br 2009, among most other countries). In general terms, the literature proposes that if there are no intentional or planned interventions of men through ICT public policies or digital inclusion programmes, the effects of technologies on the society will be more regressive than redistributive due to current or prior socioeconomic inequalities (Hargittai 2008: p.942-943; PNUD 2009: p. 211). In the prophetic words of one of the "fathers" of informational society: "The information age does not have to be the age of steppedup inequality, polarization and social exclusion. But for the moment it is" (Castells 2005: p. 403, as cited in Selwyn 2004: p. 342).

The next factor is related to the binary or simplistic ${ }^{4}$ conceptualizations of the divide. The criticism to this is sustained by authors like Hargittai (2008), Selwyn (2010) and Van Dijk and Van Deursen (2010) who have considered insufficient the idea that the mere access to technology will end inequalities. Consequently, the study of the issue has been refined to much more diverse and complex dimensions: quality of access (e.g. characteristics of equipment, connection speed), ICT effective uses (different types of usage), presence of social support networks, digital literacy or ICT skills and notions related to appropriation (Hargittai 2008: p. 937, based on a revision of several authors). ${ }^{5}$ Nonetheless, increasing the complexity of the concept started an explosion of approaches on new informational society inequalities, and today, there are almost as many perspectives as authors studying the subject (e.g. PNUD 2009; Peña-López 2009; Hargittai 2002).

In a later stage of development, some scholars have suggested that the divide must be further refined by studying simultaneous but different levels or stages at which divides exist (Hargittai 2002): Norris (2001: p. 4) signalled three levels of inequalities (between countries, within countries and in participation within countries; taken from Hargittai 2002), while DiMaggio and Hargittai (2001) proposed more complex approaches by suggesting five dimensions of possible divides (technical means, autonomy of use, use patterns, social support networks and digital skill). Van Dijk's (2005) model of successive kinds of access to digital technologies (motivational, material, skills and usage accesses) described four successive stages or kinds of access that are supposed to be cumulative (Van Dijk 2005: p. 21). Not only do we agree with this perspective, we suggest that this is the only way the divide can be conceptually and empirically addressed adequately.

\footnotetext{
${ }^{4}$ For example, as Selwyn (2004: p. 344-345) states, a position addressed by Devine (2001: p. 28) or Edwards-Johnson (2000: p. 899) at the start of divide's studies.

${ }^{5}$ Mark Warschauer (2002) was one of the first scholars to systematically promote the necessity to evolve the conceptualization of the divide, including digital capabilities and digital literacy as key factors in it (Peña-López 2009: p. 79). Peña-López argues the role played by Paul DiMaggio and Eszter Hargittai (2001a, b) was central, as they contributed enormously to the shift in focus from the dichotomist divide to digital inequalities in a more comprehensive way, including also their concern about the divide on skills (Peña-López 2009: p. 79). For a more complete synthesis, see Peña-López (2009: p. 7).
} 
Finally, we argue that there is a last stage which is still unanswered: any divide conceptualization model must also include ICT's impact on wellbeing or development by integrating the concept of "development" to the name of the subject field itself. In fact, only a few studies include this dimension on an individual or personal level.

From the approaches that could be categorized in this final stage, we have opted to present here two of the plausible hierarchical divide's conceptualizations which clearly point to the impact or outcome dimension as the last stage in the hierarchy: (1) a comprehensive (but thus complex) adaptation of Amartya Sen's capabilities approach (from now on referred to as CA) to ICT (in several texts as Alampay 2006, Zheng 2007 or Forester and Handy 2008) and (2) a more concise but nevertheless coherent and easier to operationalize divide's model based on Selwyn's approach (2004, 2010) of four hierarchical and coexisting stages of the divide (access, use, appropriation and results/outcomes).

However, before concisely describing these two alternatives, it is important to emphasize the criticism proposed by Hargittai about the oversimplification of the discussion regarding the relationship between ICT and social reproduction or mobility: even after recognizing ICT's potential effect on equity, it is naïve to suppose that ICT will nullify the pernicious effect of previous inequalities such as background social class, gender or socioeconomic status (Hargittai 2008: p. 942).

\subsection{Two Plausible Analytical Approaches: Sen's and Selwyn's Frameworks}

The selection or recommendation of a divide's analytical framework to adopt is not an easy task. There are many alternatives (as reviewed in the former sections), some classified as good, others classified as bad and probably many reasonable ones. Between all the plausible digital divide models, the most comprehensive are generally too complex or have huge barriers to entry to introduce in non-ICTD researches, and the most basic ones tend to lack a proper theoretical coherence or a wide range of application (i.e. social inequality, participation, education and health studies).

In this section, we will present and briefly discuss two different analytical frameworks in compliance with the conceptual development previously identified. As the discussion of each model will reflect, both have strengths and weaknesses, making the final selection both a matter of practicality and personal preferences.

\subsection{A Capabilities Approach-Based Analytical Framework: Exhaustive but Not Cost-Efficient}

Widely adopted in economics and poverty studies, the CA is far from an ICTspecific conceptualization. $\mathrm{CA}$ is a more general human development paradigm 
that considers the expansion of individual freedoms (or agency in CA terms) as a main development goal (Heeks and Molla 2009: p. 33). As argued by Zheng, Sen proposes that reaching a substantive level of individual freedom is the only means of objective and social development (Sen 1999, as cited in Zheng 2007: p. 2). In this sense, agency is the goal and central concept of the CA, understood as the ability to pursue and achieve goals that people value or have reason to value (Alkire 2005: p. $1-2)$.

Due to this general approach, CA can be applied to almost any area of social research, particularly at individual or household levels; e-development, ICTD or information society is no exception.

The driving idea of CA's application to ICT, in accordance to the mentioned hierarchical logic we adhere to, is that the possession of ICT does not irreducibly result in an increase of wellbeing. While access to these goods is necessary, it is insufficient for assuring ICT's impact on the capabilities and performances of people. For ICTs to have a positive effect on wellbeing, CA's authors argue that a mediation or simultaneous presence of several other factors is required (Alampay 2006: p. 9).

Although Fig. 1 tries to present a condensed representation of CA's analytical framework to assess ICT's impact, complexities of the approach itself and its glossary render it important to further explain some of its core concepts. According to the objectives of this section, there are three key (functioning, capabilities and commodities) and two subsidiary (characteristics, conversion factors) concepts of CA to work with.

ICT's goods and services are the first entry of the process. Although the concept of commodities is probably more mainstream, its interaction with capabilities is not as direct and has major consequences for the CA and scope of this document. Zheng (2007: p. 2) explains that for Sen, commodities become relevant in so far as their characteristics enable the individuals to generate capabilities from their properties.

In the opposite corner of the figure, functionings refer to the huge number of activities and states that make the actual wellbeing of individuals; they are the "beings and doings" of people (Zheng 2007: p. 2). On the other hand, capabilities reflect the concept of freedom that was previously emphasized by the notion of

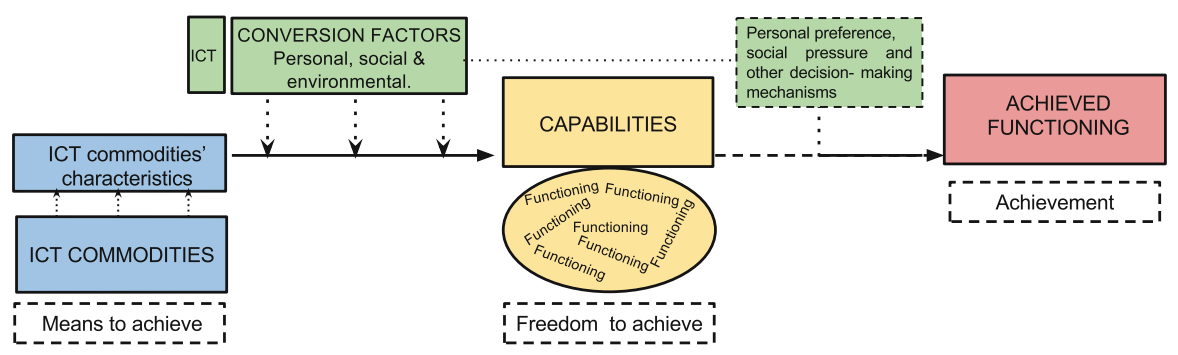

Fig. 1 Adaptation of capabilities approach to ICT and wellbeing (Source: Based on Zheng (2007) (Adapted from Robeyns (2005)) and Heeks and Molla (2009) (based also on Zheng's work)) 
agency: these refer to a "pool" of performances to which an individual can access at any given time (Alkire 2005: p. 1; Zheng 2007: p. 2). Nevertheless, effective functionings are the only things researchers would probably be able to assess in the majority of studies: well-paid jobs, formal education achievement, income, etc. This would be the area or dependent variable in which ICT may have an impact.

However, Fig. 1 shows that CA's framework is even more complex, in the way that not all individuals are able to convert or generate capabilities in equal rates from the same features. This is due to differences in their conversion factors, which may be personal (i.e. literacy, cognitive ability, gender), social (i.e. culture, norms, values) and environmental (Zheng 2007: p. 2).

Conversion factors may also be considered capabilities themselves, which mediate the conversion of ICT's characteristics (Alampay 2006: p. 9; Garnham 1997: p. 32): literacies, knowledge on the use of ICT and the understanding of the implications of using information as a resource, to name just a few of them. Moreover, ICT commodities may also act as conversion factors or conversion factor enablers (Heeks and Molla 2009: p. 34).

At this point, it is probably clear to the reader that the problem with CA is that as strong and comprehensive its theoretical and philosophical framework is, it is a very difficult framework to understand and apply, especially to a non-ICT researcher. As Heeks and Molla (2008: p. 33) argue, CA is "quite a dense set of ideas that can be hard to understand and translate into practical evaluation terms". For the sake of lowering barriers to entry to the ICT field, while CA provides a strong theoretical model on ICT's impact on wellbeing, it is not the best candidate to use as a firstentry analytical framework.

\subsection{A Basic Analytical Model: Selwyn's Hierarchical Approach}

Selwyn's digital divide model $(2004,2010)$ is not only comprehensive, but also specific to the ICT4D field, and presents adequate alternatives and solutions for the already mentioned problems of the conceptual development of the term.

Having a more direct and specific ICT's impact focus, Selwyn considers that it is essential to conceptualize the divide "as a hierarchy of access to various forms of technology in various contexts, resulting in differing levels of engagement and consequences" (Selwyn 2004: p. 351). Basing an analytical framework on this approach seems at least logically correct and reasonable.

As Fig. 2 illustrates, the hierarchical logic is expressed in the plausible but not assured progression from one stage to another, culminating with potential shortterm or long-term benefits (Selwyn 2010: p. 351). However, following authors who adopt this approach to the Latin American context, we believe that "more than distinguishing development phases, it is necessary to think in gap levels that occur simultaneously" (Sunkel et al. 2010: p. 12). 


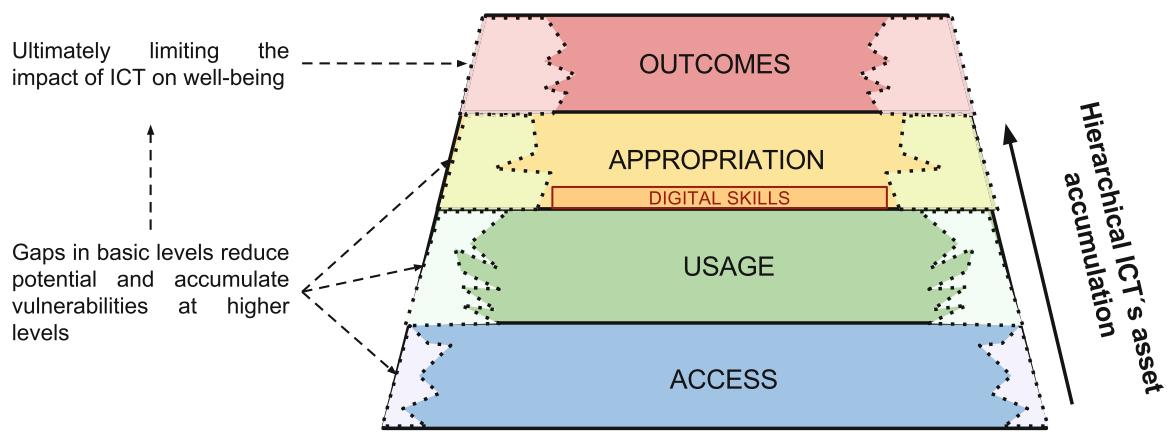

Fig. 2 Adaptation of Selwyn's digital divide theoretical model (Source: Dodel (2013), based on Selwyn (2010) and Sunkel et al. (2010))

We think that not only assets accumulate, but also disadvantages or liabilities. As Fig. 2 shows, the gaps in lower levels of the divide have consequences to the whole chain of digital achievements and, thus, to the chances of ICT having a positive impact on wellbeing.

As obvious as it may seem at first glance, this disadvantage accumulation is a key point of the framework: ICT's effect is non-assured; it could be null, positive or even some combinations of assets, i.e. of low access and poor usage; and it may have negative effects on several aspects of wellbeing. We think it is useful to remember that we are assessing ICT's effect and not blindly preaching about its potential; it is not only logical but scientifically desirable, we think, to find empirical evidence of situations in which ICT's effect is not clearly positive.

\subsection{Divide Stages}

Going back to the use of the approach as an ICT's impact assessment framework, we have opted to simplify Selwyn's proposed five stages $(2004,2010)$ into four (collapsing formal and effective access into one category of access only). ${ }^{6} \mathrm{We}$ suggest assessing four levels of digital achievements: access, use, appropriation and outcomes.

The denominations of Selwyn's proposed stages have a secondary advantage: when compared to other models, the simplicity of the terms used makes the framework almost instantly understandable. Obviously, there are some technicalities and nuances, but mostly, this accessibility is one of the strengths of this approach.

A second basic component of this model is that even after taking into account the specific but shareable conceptualizations of each stage, they should not be

\footnotetext{
${ }^{6}$ Following Sunkel et al. strategy (2010: p. 12).
} 
regarded as static and dichotomic. Besides this general definition, each stage's most appropriate indicator differs in relation to the outcome or impact in which ICT's effect must be assessed: the outcome dimension.

Having these two main guidelines in mind, we will address each dimension in some detail in order to discuss the approach limitations. The access stage refers to the availability of the "hard" components of the divide: from general infrastructure and connectivity to specific hardware and software with different purposes.

Selwyn gives a special emphasis on the importance of avoiding falling in analysis centred on the formal or "theoretical" aspect of the concept. ${ }^{7}$ Access assessment should focus on accessibility and effective availability of ICT goods. As Selwyn states, we believe that any realistic notion of access must be defined from the demand's or individual's perspective (Selwyn 2004: p. 347).

Usage refers not only to a use or not use dichotomy but also to the usage frequency, places of use, the kind of activities conducted through ICT and the amount of content generation and consumption, among others (e.g. AGESIC-INE 2010; CETIC.br 2009).

There is an enormous amount of usage measurement possibilities, probably even more than on the access stage, making the selection of one or a small quantity of indicators more arbitrary. As we will develop the idea in the next section, the final stage or dependent variable in which the study tries to assess the impact of ICT should be used as a guideline for the selection of the most relevant usage indicators.

In turn, appropriation is a bit more complex and difficult to define and carry out due to its predominantly subjective character. According to Selwyn, appropriation can be understood as "meaningful use of ICT ... where the 'user' exerts a degree of control and choice over the technology and its content, thus leading to a meaning, significance and utility for the individual concerned" (Selwyn 2004: p. 349).

In this particular case, alternative definitions of appropriation are very useful, not only due to the ambiguity of the notion but also as they provide more clues about the application of the concept in the literature.

As an example, Prado et al. (2009: p. 87) propose that appropriation must be understood as "the integration and adoption process within user's daily life". They emphasize the fact that technology appropriation results from routine and stand on this idea to measure the concept. ${ }^{8}$

Finally, as we previously hinted, the last stage of the framework refers to what we believe is the sociologically key issue: the outcome, impact and consequences of accessing and using ICT - the ends of engagement of ICT use (Selwyn 2004: p. 349).

\footnotetext{
${ }^{7}$ Many studies about the education gap tend to use excessively gross indicators of digital access, such as "percentage of educational institutions with PC access", which do not take into account the PC/student ratio or the possibility of use or effective use of this ICT by students (Claro et al. 2011).

${ }^{8}$ For them, it is necessary to inquire about the conditions facilitating the technology, perception of the technology as an object, the simplicity of use, perception of usefulness, auto-efficiency, technology in use and satisfaction with the same (Prado et al. 2009: p. 87).
} 
Moreover, this is the area of expertise of the non-ICT researcher: the dependent variable in which he or she is much more skilled than the actual ICTD and information society veterans. He or she will construct better dependent variables, studying not only ICT's effect but several other dimensions that affect these outcomes, controlling confounding effects. For ICTD studies though, this is crucial as this logic enormously strengthens the methodological design and testing of ICT's impact.

Another aspect in which this stage is crucial is related to the choice of the operationalization of the first 3 stages of the divide. As we will elaborate, this task not only depends on the conceptual definition of each stage but also on the dependent variable. This variable should be taken as the main guide to set the bar in what we would like to study about access, usage or appropriation: they should have a logical connection with the sought outcome. The last section of this chapter will expand on this topic and present a fully developed example/case of use of this approach.

\subsection{Limitations: Motivational Stage and Linkage with General Socioeconomic Inequality}

Aside from the (maybe too) general approach (which some may consider as a limitation, but we consider it one of its main strengths), the main weakness of Selwyn's model refers both to the lack of a motivational component and to the absence of a direct theoretical linkage with non-ICT inequalities.

Despite some people conceptualizing a motivational stage as the first level of the divide (Van Dijk J. 2005), motivations or attitudes towards ICT are complex, multicausal and affect all of the three ICT stages of the proposed divide model in circular ways. From the household perspective, positive attitudes towards ICT could encourage the purchase of digital commodities, but on the other side, without the possibility of access, individuals will not be able to get to the usage stage even if absolutely motivated. Also, motivation could increase the chances of usage (Van Dijk 2005), but usage could lead to the acknowledgement of what can be achieved with ICT and, thus, motivation or appropriation or both.

The second weakness of the version we adopted from Selwyn's approach is the lack of any direct linkage within ICT inequalities and socioeconomic-based ones (e.g. social class, Bourdieu's capitals). It is not that Selwyn forgets to include these subjects (Selwyn 2004), but for the sake of simplification, we excluded them in the specific framework.

Obviously, differences in access, usage, appropriation and also motivation related to ICT are determined, at least in part, by socioeconomic inequity (Dodel 2013), and at least some kind of theoretical linkage between the two was already stated in this chapter (the regressive effect of ICT without public policy intervention). 


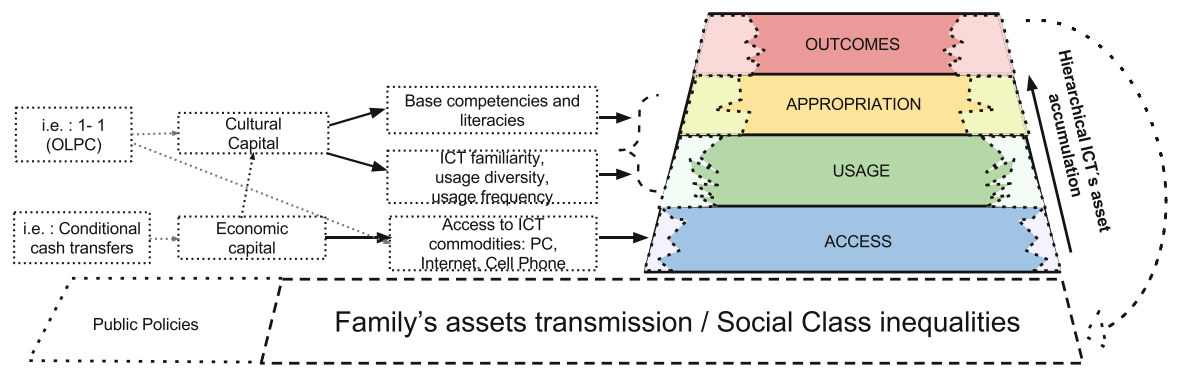

Fig. 3 Adaptation of Selwyn's digital divide theoretical model taking into account previous socioeconomic inequalities (Source: Dodel (2013), based on Selwyn (2010) and Sunkel et al. (2010))

We think these two limitations are not fatal flaws to the analytical framework, and as Fig. 3 shows, we propose a broader version of the model, taking into account both socioeconomic inequality and motivation/attitudes by including a first and parallel source of inequity: family's asset transmission and, in a lesser amount, public policies.

Borrowing some of Bourdieu's notions (Bourdieu 1986), we propose that similar mechanisms that determine the social class or status prior to any digital divide affect economic, cultural and other capitals of the families, which thus affect both the means to access ICT and the attitudes and base competencies needed to use and engage with technology.

Nevertheless, Fig. 3 points to a third problem related to ICT's impact assessment in general. As ICT inequalities are caused by prior socioeconomic disparities, without the proper confounding controls, ICT's relation with any wellbeingdependent variable could be overestimated or even completely spurious. One example of this problematic phenomenon would arise if a researcher heads towards the assessment of the effect of a household's Internet connection on educational or health achievements without controlling any measure of income inequality: even if there is a marginal ICT effect, most of the observed relationships would probably fall under the effect of income inequalities. Thus, contextualizing ICT and wellbeing relationship in other sociological issues, both as theoretical and confounding control, stands as crucial as considered in any serious ICT's impact study.

Summarizing, we think Selwyn's approach limitations need to be taken into consideration, but they do not disable its application. Moreover, even if we think Fig. 3 provides a more comprehensive framework, in most of the cases which this chapter addresses (non-ICT-specific research), the basic model (Fig. 2) should be chosen by taking the parsimony criteria.

In the next section, we will present a specific case of use and discuss some criteria on how to apply this framework. 


\section{Operationalization: A Case of Use on the Study of Digital Skills' Effect on Education-to-Work Transitions}

\subsection{Research Problem}

Important cumulative experience exists regarding the increasing diversification of formal education and labour market pathways (from now on referred to as pathways) of contemporary Uruguayan society's young people and their serious consequences on the processes of social inequality reproduction and the beginning of social mobility. As the effects of several socioeconomic variables on these pathways have already been stated (socioeconomic origin inequalities, gender, educational achievements, early labour market pathways), we suggest the existence of another determining key factor for the opportunities of social welfare in informational contemporary societies, which has not yet been addressed in the education-to-work transition field: the digital skills (e-skills).

The preceding paragraph summarizes the main hypothesis of the SIRCA II's quantitative research on which the author of this chapter has participated: "ICT and Welfare policies: Digital skills' impact on formal education and labour market pathways of young Uruguayans evaluated by Programme for International Student Assessment (PISA) 2003 (Panel study)". The dependent variable in this research was young Uruguayans' early occupational achievements (if they were able to access a white-collar job at or before the age of 19).

\subsection{Application Based on the Analytical Framework}

We propose a short but useful guideline for the operational process, which can be summarized in a number of steps, with a general, overarching guideline to use an up-to-down strategy: i.e. start from the dependent variable, and then go to the appropriation stage, then usage and finally access (when available):

1. Starting from a theoretical relevance perspective: which ICT dimension is the one which could have a direct impact on the dependent variable?

2. If you are producing primary data, think ahead on how you are going to measure such data. If you are using secondary data, browse your questionnaires or interview guides in order to search for potential variable candidates.

3. In order to select or create a specific variable in a stage, choose wisely based on the characteristic of the study's universe: the level of dissemination of the selected ICT's achievement on the population could be too scarce or almost universal. "Set the bar" using an indicator of reasonable spread.

4. Repeat steps 1 to 3 through lower levels of the divide. 


\subsubsection{Linkage Between ICT and the Dependent Variable}

Step one is the most complex but also crucial in an adequate operationalization process. As we were researching education-to-work transition and conceived ICT as a key factor in them, we first needed to establish the theoretical links between our research problem (early labour market achievements) and ICT field; we will briefly present this conceptualization.

As Mills and Blossfeld argue (2006: p. 1), young people in industrialized nations have experienced significant changes in the transition to adulthood in the past decades, particularly due to the rapid dissemination of knowledge networks and the expansion of the new technologies. The new technological or informational paradigm (Castells 2005: p. 88) will severely affect the chances of getting a job or accessing quality occupations or both, especially in the contexts of great socioeconomic inequalities (e.g. Latin America). Thus, further increasing the importance of ICT achievements due to skill-biased technological change, Cobo (2009: p. 3) explains that "The acquisition of ICT competencies is increasingly becoming a key requirement for employability".

The way we conceive the problem, it is neither the hardware nor the mere use that is relevant for the desired outcomes. Achievements on a higher stage of the divide are necessary to have skills or abilities related to ICT that could impact on occupational outcomes. We propose that these skills correspond to a low level of the third divide stage: e-competencies and e-skills are very basic types of ICT appropriation (Dodel 2013).

\subsubsection{The Data}

The microdata which constitutes the research's empirical base comes from PISA-L Uruguay (Boado and Fernández 2010), the first panel follow-up survey for PISA (2003) carried out in 2007 to a sample of 2,201 Uruguayan young people (between 19 and 20 years old at that time).

Application of the different divide's dimensions was carried out based on the variables gathered by PISA's original ICT questionnaire and some ICT variables from the student's questionnaire (both from 2003). It is relevant to stress that this data was collected when respondents were 15 years old, giving us strong arguments (temporal precedence) to talk about causality in their effect on dependent variable at the age of 19 .

The first of these questionnaires contained several specific ICT variables regarding access (availability of ICT goods for use at home, school and other places), usage (from the year of first use and general frequency to the frequency of specific activities performed within certain programmes), e-skills (perception or confidence on his or her ability to perform certain tasks) as well as attitude towards ICT, among others. ${ }^{9}$

\footnotetext{
${ }^{9}$ For further details, see the PISA 2003 Information Communication Technology Questionnaire.
} 
Although it would be possible to develop an exhaustive analysis based on this whole information, given the research design choices (we chose to prioritize confounding control with an already large amount of variables), we opted to select only four ICT indicators as proxy of achievements at the three first levels of the divide.

The main criterion for selecting these indicators was to focus on a reduced number of important digital achievements, identifying key aspects of each dimension of the divide without overloading the already broad group of variables to be included in multivariate models.

\subsubsection{The Proper Application}

\section{Appropriation: Office User E-Skills}

Not addressing here all the complexities of the final construct used in the research (see Dodel 2013 for a similar discussion), we opted to create an e-skills variable based on the already stated theoretical conceptualization: a measure of the e-skills (probably) required on a white-collar job.

Therefore, we decided to build a dichotomous variable indicating if the young individual can perform on his or her own the vast majority of skills considered as part of the solid core of ICT tools required to participate in a socially and economically valuable activity.

We choose to "set the bar" on at least eight out of nine of the skills related (as a whole) to a standard office-like user, a cluster of skills shared by $27 \%$ of the survey's population: opening a file, editing a file, saving a file, printing a file, downloading a file from the Internet, sending e-mails, attaching a file to an e-mail, creating graphs in excel or similar programmes and creating a PowerPoint (or similar programme) presentation.

\section{Usage: Early ICT Socialization and Frequent Persistent Use}

In turn, usage achievement indicators involve a much greater number of alternatives (20 questions). However, in line with the conceptual framework, we reduced the number of variables in this field to two: according to Cobo (2009) and our own analytical model in Fig. 3, it is possible to state that (1) an early socialization in ICT and (2) ICT frequent use are key as a platform for the subsequent e-skills achievement.

In this sense, we choose two relatively high usage achievements, shared by 25 and $38 \%$ of the population, respectively: (1) years using a PC (5 years or more) as an "early" ICT socialization proxy and (2) the most frequent use of the PC (almost daily) as a regularity or routine indicator of use. 


\section{Access: A Significant Kind}

Having several technologies available to use as indicators on this stage, we dismissed connectivity because of the low penetration rate at Uruguay in 2003 but also because PISA's questionnaire conceived the Internet more like an activity or use of the PC rather than as a commodity by itself.

Then, we chose an access indicator based on two criteria. On the one hand, according to Selwyn (2004) and Dodel (2013), we stated the democratizing effect of $\mathrm{PC}$ access at home for the subsequent levels of the divide. On the other hand, also in accordance with Selwyn (2004), we wanted to emphasize the effective provision of ICT goods that enables the subject to use them for the desired or required activities. In this sense, we opted for a relatively common (38\%) but rather "high" indicator of access' achievement: the availability of a PC at home where the young individual can do schoolwork if needed. ${ }^{10}$

Figure 4 shows a visual synthesis of the application of ICT's impact analytical framework on a more complete representation of the education-to-work transition research design. Obviously, the design has some limitations and improvements could be done to the research, but we think the case of use exemplifies more than adequately a reasonable conceptualization and application of an ICT's impact research.

Based on this framework and operationalization and fitting strategies presented in Fig. 4 (strong control of the ICT's working hypothesis under several hypothesis blocks), the research was able to assess an "e-skills effect" on pathways. Eskills constitute a significant part of the explanatory component in the variance of occupational achievements at 19-20 years old. Despite the fact that their effect is not the strongest, having a quantum of e-skills (an office-like level) at 15 years old compared to not having them increases (ceteris paribus) the chances of getting a white-collar occupational achievement at 19-20 years old by $60 \%$.

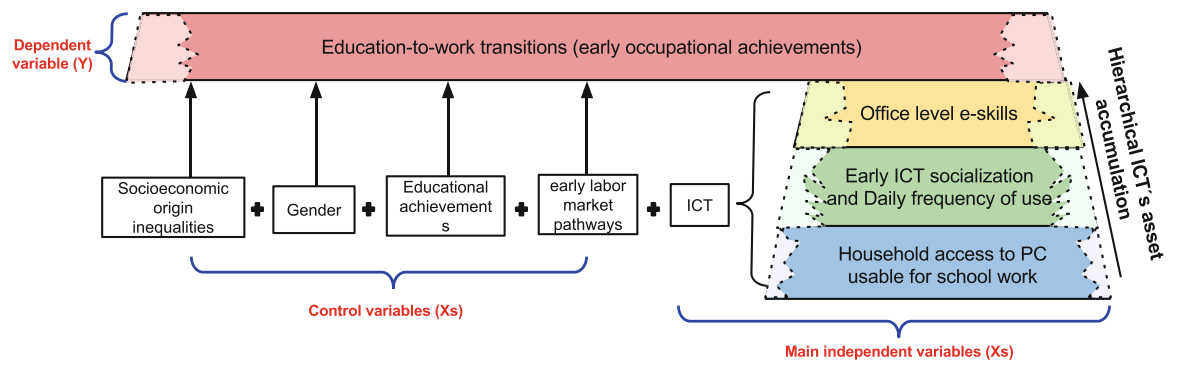

Fig. 4 Visual representation of "ICT and Welfare policies: Digital skills' impact on formal education and labour market pathways of young Uruguayans evaluated by Programme for International Student Assessment (PISA) 2003 (Panel study)" using the proposed analytical framework

\footnotetext{
${ }^{10}$ The original question is: "Which of the following do you have in your home? A computer you can use for schoolwork"
} 


\section{Synthesis and Implications}

This chapter proposed an analytical framework in order to guide the assessment of ICT's impact on wellbeing. We argued that the amount of polysemy and lack of common basic guidelines in ICT fields constitute one of the main barriers for the incorporation of ICT into a broader research problem spectrum (outside the ICT researchers' communities) and, consequently, to widen ICT's impact research. After a synthesis of the historical development of the digital divide concept, we discussed and developed two plausible analytical models to assess ICT's impact on wellbeing, finally opting for a framework based on Selwyn's approach. We supported the idea that the testing of any ICT-related hypothesis should analyse, at least and when possible, three stages of hierarchical digital achievements (access, usage and appropriation) plus one last divide stage: ICT's outcomes (measured by the effect of previous stages on the dependent wellbeing variable). Finally, we propose five guidelines for the applications of this framework and present an actual case of use, showing how this framework guided the research design in a study of the effect of e-skill on education-to-work transitions: use an up-to-down strategy from higher to lower stages of the divide, start from a theoretical relevant perspective, assess the possibilities the data or research instruments enable for each stage and repeat this strategy for the lower levels of digital inequalities.

To conclude, we would like to emphasize that this document does not aim to become a final analytical framework to research ICT's impact on wellbeing as it is only a first and basic guide for orientation purposes.

We conceive this document as a first step in the task of expanding ICT's impact research and discourse outside the information society and ICTD community. It is our belief that there is a need to construct quality and cost-efficient research instruments that will enable a wider spectrum of social researchers, those not focused on information society, to introduce ICT assets (access, usage, appropriation) as independent variables to their studies. This would also enhance our opportunity to study ICT's impact in a much wider and more diverse array of subjects.

Open Access This chapter is distributed under the terms of the Creative Commons Attribution Noncommercial License, which permits any noncommercial use, distribution, and reproduction in any medium, provided the original author(s) and source are credited.

\section{References}

AGESIC-INE. (2010). Encuesta de Usos de las Tecnologías de la Información y Comunicación. Retrieved from http://www.ine.gub.uy/encuestas\%20finalizadas/tics2011/tics2011.asp

Alampay, E. (2006). Beyond access to ICTs: Measuring capabilities in the information society. International Journal of Education and Development using ICT, 2(3), 4-22. ijedict.dec.uwi. edu/include/getdoc.php?id=1343

Alkire, S. (2005). Capability and functionings: Definition \& justification. Human Development and Capability Association. Retrieved from http://www.capabilityapproach.com/pubs/HDCA_ Briefing_Concepts.pdf 
Boado, M., \& Fernández, T. (2010). Trayectorias académicas y laborales de los jóvenes en Uruguay. El panel PISA 2003-2007. Montevideo: FCS. Retrieved from http://www.fcs.edu. uy/pagina.php?PagId=869

Bourdieu, P. (1986). The forms of capital. In J. Richardson (Ed.), Handbook of theory and research for the sociology of education (pp. 241-258). Westport: Greenwood.

Bunge, M. (1999). Buscar la filosofía en las ciencias sociales. México: Siglo XXI.

Castells, M. (2005). La era de la información. Economía, Sociedad y Cultura (La Sociedad en Red, Vol. 1). Madrid: Alianza.

Cetic.br. (2009, 2011). Pesquisa sobre o Uso das TICs no Brasil-2009/Survey on the use of ICTs in Brazil [On line]. Retrieved from http://www.cetic.br/tic/2009/

Claro, M., Espejo, A., Jara, I., \& Trucco, D. (2011). Aporte del sistema educativo a la reducción de las brechas digitales. Una mirada desde las mediciones PISA (Documento de proyecto LC/W.456). Retrieved July 21, 2013, from http://www.eclac.org/publicaciones/xml/4/45634/ Aporte_del_sistema_DCTO_W_NR_con_ultimas_indicaciones_editx.pdf

Cobo, R. (2009). Strategies to promote the development of e-competencies in the next generation of professionals: European and International trends (SKOPE Issues Paper Series, Monograph No. 13). Retrieved July 21, 2013, from www.skope.ox.ac.uk/sites/default/files/Monograph\%2013. pdf

Devine, K. (2001). Bridging the digital divide'. Scientist, 15(1), 28.

Dimaggio, P., \& Hargittai, E. (2001). From the digital divide to digital inequality: Studying Internet use as penetration increases (Working Paper Series Number 15). Princeton: Princeton University Center for Arts and Cultural Policy Studies. (http://www.princeton.edu/ artspol/ workpap/WP15\%20-\%20DiMaggio+Hargittai.pdf)

Dodel, M. (2013). Las tecnologías de la información y comunicación como determinantes del bienestar: el papel de las habilidades digitales en la transición al empleo en la cohorte PISA (Sociology M.A. dissertation). Montevideo: Universidad de la República.

Edwards-Johnson, A. (2000). Closing the digital divide. Journal of Government Information, 27(6), 898-900.

Fink, C. \& Kenny, J. (2003). Whither the digital divide? Info, 5(6), 15-24. Retrieved July 21, 2013, from http://www.itu.int/wsis/docs/background/themes/digital_divide/fink-kenny.pdf

Flor, A. G. (2001). ICT and poverty: The indisputable link. In SEARCA, paper for the third Asian development forum on "Regional Economic Cooperation in Asia and the Pacific" (pp. 11-14). Bangok: Asian Development Bank. http://www.academia.edu/1110532/ICT_and_ poverty_the_indisputable_link. http://ftp.unpad.ac.id/orari/library/library-ref-ind/ref-ind-1/ application/poverty-reduction/!\%20ICT4PR/ICT\%20and\%20poverty\%20-\%20the\%20link $\% 20$ (WB\%20Report).pdf

Foster, J., \& Handy, C. (2008). External capabilities (OPHI Working Paper 8). Oxford: University of Oxford.

Garnham, N. (1997). Amartya Sen's capabilities' approach to the evaluation of welfare: Its application to communication. Javnost - The Public Journal of the European Institute for Communication and Culture, 4(4), 25-34.

Hargittai, E. (2002). Second-level digital divide: Differences in people's online skills. First Monday, 7(4). http://firstmonday.org/htbin/cgiwrap/bin/ojs/index.php/fm/article/view/942/864. URL: http://firstmonday.org/issues/issue7_4/hargittai/index.html

Hargittai, E. (2008). The digital reproduction on inequality. In D. Grusky (Ed.), Social stratification: Class, race, and gender in sociological perspective (pp. 936-944). Boulder: Westview Press.

Heeks, R. B., \& Molla, A. (2009). Impact assessment of ICT-for-development projects: Compendium of approaches (Development Informatics Working Paper No. 36). Manchester: University of Manchester. http://www.sed.manchester.ac.uk/idpm/researcpublications/wp/di/ di_wp36.htm

ITU-International Telecommunications Union. (2010). Informe sobre el Desarrollo Mundial de las Telecomunicaciones/TIC de 2010: Verificación de los objetivos de la CMSI [Resumen ejecutivo]. CH-1211. Ginebra: UIT 
Kaztman, R. (2010). Impacto social de la incorporación de las nuevas tecnologías de información y comunicación en el sistema educativo (Serie Políticas Sociales $\mathrm{N}^{\circ} 166$. CEPAL). Retrieved July 21, 2013, from http://www.eclac.cl/publicaciones/xml/4/41364/sps166-kaztman-gsunkelalis-2010.pdf

Lankshear, C., \& Knobel, M. (Eds.). (2008). Digital literacies: Concepts, policies and practices. New York: Peter Lang.

Mills, M., \& Blossfeld, H. P. (2006). Globalization, uncertainty and changes in early life courses. A theoretical framework. In H.-P. Blossfeld, E. Klijzing, M. Mills \& K. Kurz (Eds.), Globalization, uncertainty and Youth in society. New York: Routledge.

Moreira, N. (2010). Acceso y uso de las Tecnologías de la Información y Comunicación en los jóvenes evaluados por PISA 2003-2006 en Uruguay (Sociology M.A. dissertation). Montevideo: Universidad de la República.

Norris, P. (2001). Digital divide: Civic engagement, information poverty, and the internet worldwide. Cambridge: Cambridge University Press.

OECD. (2010). Are the new millennium learners making the grade? Technology use and educational performance in PISA. Paris: Educational Research and Innovation.

Peña-López, I. (2009). Measuring digital development for policy-making: Models, stages, characteristics and causes. Information and Knowledge (Doctoral dissertation). Barcelona: Universitat Oberta de Catalunya.

PNUD - Programa de las Naciones Unidas para el desarrollo. (2009). Informe sobre desarrollo humano para Mercosur, Innovar para incluir: jóvenes y desarrollo humano, 2009-2010. Tucuman: Libros del Zorzal.

Prado, C., Romero, S., \& Ramírez, M. (2009). Relaciones entre los estándares tecnológicos y apropiación tecnológica. Enseñanza \& Teaching, 27(2), 77-101.

Reig, D. (2012). Disonancia cognitiva y apropiación de las TIC. Telos, 90, 9-10.

Rivoir, A., Baldizan, S., \& Escuder, S. (2010, septiembre). Plan Ceibal: acceso, uso y reducción de la brecha digital según las percepcio-nes de los beneficiarios. In IX Jornadas de Investigación de la Facultad de Ciencias Sociales. Montevide: Universidad de la República.

Robeyns, I. (2005). The capability approach: A theoretical survey. Journal of Human Development, 6(1), 93-117.

Selwyn, N. (2004). Reconsidering political and popular understandings of the digital divide. New Media \& Society, 6(3), 341-362.

Selwyn, N. (2010). Degrees of digital division: Reconsidering digital inequalities and contemporary higher education. In Redefining the digital divide in higher education [online monograph]. Revista de Universidad y Sociedad del Conocimiento (RUSC), 7(1). UOC. ISSN 1698-580X. http://rusc.uoc.edu/ojs/index.php/rusc/article/view/v7n1_selwyn/ v7n1_selwyn. Accessed dd/mm/yy.

Sunkel, G., Trucco, D., \& Möller, S. (2010). Aprender y enseñar con las tecnologías de la información y las comunicaciones en América Latina: potenciales beneficios (Serie Políticas Sociales 169). Retrieved July 21, 2013, from http://www.eclac.org/publicaciones/xml/9/42669/ sps-169-tics-aprendizajes.pdf

Thatcher, A., \& Ndabeni, M. (2011). A psychological model to understand e-adoption in the context of the digital divide. In J. Steyn \& M. Johanson (Eds.), ICTs and sustainable solutions for the digital divide: Theory and perspectives. Hershey: Information Science Reference.

Van Dijk, J. (2005). Deepening digital divide: Inequality in the information society. Thousand Oaks: Sage.

Van Dijk, J., \& Van Deursen, A. (2010). Inequalities of digital skills and how to overcome them. In E. Ferro, Y. K. Dwivedi, J. R. Gil-Garcia, \& M. D. Williams (Eds.), Handbook of research on overcoming digital divides: Constructing an equitable and competitive information society (pp. 278-291). New York: Information science Reference.

Warschauer, M. (2002). Reconceptualizing the digital divide. First Monday, 7(7). doi:http://dx.doi. org/10.5210/fm.v7i4.942. 
White, D., Gunasekaran, A., Shea, T., \& Ariguzo, G. (2011). Mapping the global digital divide. International Journal of Business Information Systems, 7(2), 207-219.

Zheng, Y. (2007, May). Exploring the value of the capability approach for e-development. Proceedings of the 9th international conference on Social Implications of Computers in Developing Countries, San Pablo. 